\title{
Yield Response of Soybean to Drought Stress under Different Fertilizer Level
}

\author{
Ki-Cheol Eom*, Pil-Kyun Jung, Mun-Hwan Koh, Young-Sook Kim, and Kyung-Eun Lee
}

Sejong Institute of Data Analysis (SEIDA), Suwon 443-766, Korea

(Received: June 13 2013, Accepted: July 5 2013)

This study was conducted to investigate the yield response of soybean to drought stress in 1984 and 1986 at the experiment field of the National Academy of Agricultural Science using experiment plots with different soil water tension and fertilizer levels. The average yield response factor (YRF) of soybean to evapotranspiration (ET) calculated as $[(\mathrm{Ya} / \mathrm{Ym}) /(\mathrm{ETa} / \mathrm{ETm})]$, where $\mathrm{Ya}$, average yield; $\mathrm{Ym}$, maximum yield; ETa, average ET; and ETm, maximum ET, was 0.91 with the range from 0.74 to 1.16 . Relationship between yield index (YI = $[\mathrm{Ya} / \mathrm{Ym}])$ and evapotranspiration index $(\mathrm{ETI}=[\mathrm{ETa} / \mathrm{PET}])$ was $\mathrm{YI}=\mathbf{0 . 8 7} \cdot(\mathrm{ETI})+0.09$. Relationship between YI and the maximum soil water tension (Hmax) was YI = 1.23 - 0.23 $\log ($ Hmax). Relationship between YI and the days of drought stressed (Dr) was $Y I=0.877 \cdot \exp (-0.01 \cdot D r)$. The relation between $Y I$ and fertilizer level $(\mathrm{F})$ was $\mathrm{YI}=\mathbf{- 0 . 2 1} \cdot \mathrm{F} 2+\mathbf{0 . 3 6} \cdot \mathrm{F}+\mathbf{0 . 3 3}$, under very serious drought condition as the maximum soil water tension was $0.3 \mathrm{MPa}$.

Key words: Drought index, Yield response factor, Evapotranspiration index

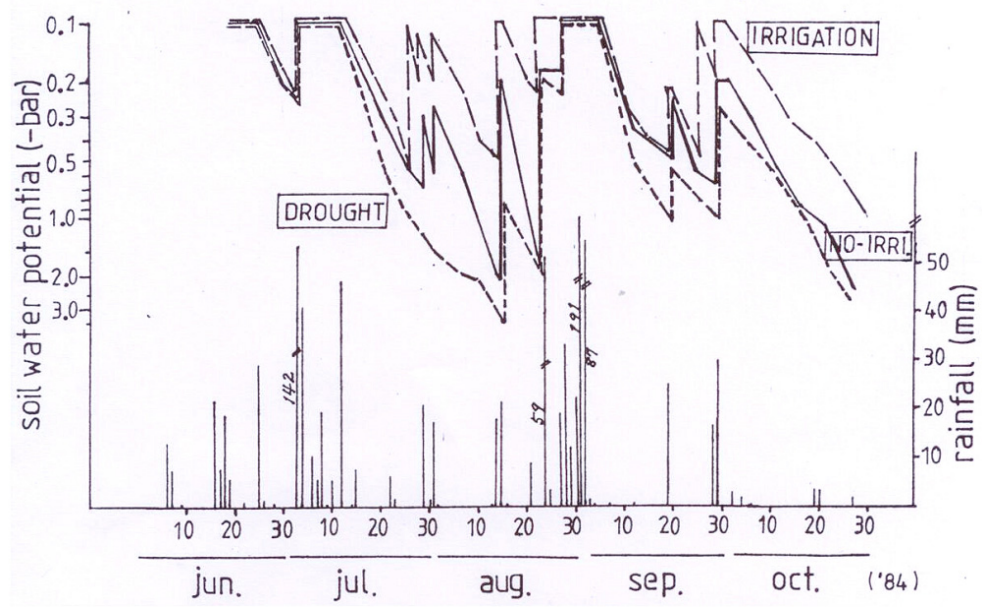

Changes in the soil water potential of soybean root zone and rainfall

*Corresponding author : Phone: +821088568765, E-mail: kceom6578@hanmail.net

${ }^{\S}$ Acknowledgement: This study was carried out with the support of "Cooperative Research Program for Agricultural Science \& Technology Development (Project No. PJ009870)”, Rural Development Administration, Republic of Korea. 


\section{Introduction}

우리나라 기상조건은 거의 해마다 농민에게 한발과 홍수 를 겪게 한다고 해도 과언이 아닐 것이다. 물론, 연간 기후 변화는 일률적인 상승 또는 하강 경향을 보이는 것이 아니 고 주기적인 경향을 보이며, 대기의 증발요구량에 대한 지 표인 잠재 증발산량은 우리나라의 경우 약 19 년을 주기로 변동되고 있기 때문에, 한발의 정도 또한 주기성을 나타내 게 되고 매년 그 정도는 약간의 차이가 있겠지만 (Eom et al., 2011), 한발 스트레스에 의한 콩 수량 감수율은 $21 \%$ 44\%로 보고되어 있어 (RDA, 1994; Son et al., 1996; Kim et al., 2000; Lee et al., 2004), 그 정도가 매우 심각한 편 이다. 그러나 한발과 관련한 국내의 재배시험 연구 결과는 매우 적다. 특히 본 연구에서처럼 한발처리를 한 포장재배 시험을 통한 한발관련 지표개발 연구는 찾아보기 어려웠다. 이는 첫째, 포장시험을 하면서 한발처리를 할 수 있는 시설 예를 들어 강우차단 시설 등을 갖추어야 하고, 둘째, 한발 조건과 대비 연구할 수 있는 관개 시스템이 구축되어야 하 며, 셋째, 콩 재배 포장에서 토양 비파괴 방식에 의한 근권 (최소 $50 \mathrm{~cm}$ 깊이 이하)의 토양 수분 함량 및 토양 수분 Potential (또는 Tension)을 파종기부터 수확기까지 전 생육 기간 동안 경시적 측정을 하여야 하며, 넷째, 시험포장에 기 상 관측 시스템과 Lysimeter 시설이 있어야 하는 어려움 때 문이라고 사료된다 (Eom et al., 2009). 따라서 본 연구는 한발이 심하였던 과거 (1984년, 1986년)에 상기 4가지 조건 을 구비한 상태에서 콩을 시험 재배하며 조사 분석한 결과 를 이용하여, 시험 data의 재해석을 통한 콩의 수량과 관련 되는 지표 (Index)들을 개발하여 콩의 한발에 대한 수량반 응을 구명코자 하였다.

\section{Materials and Methods}

본 연구는 한발이 극심하였던 1984년과 1986년에 공시토 양이 본량 사양토인 현 국립농업과학원 (구 농업기술연구 소) 시험포장 $(3 \mathrm{ha})$ 에서 콩 (품종: 광교)을 공시작물로 하 여 1984년도 시험구 처리는 단구제로 하면서 각 처리구 면 적은 $200 \mathrm{~m}^{2}(10 \mathrm{mx} 20 \mathrm{~m})$ 이었으며, 시비량을 표준시비 량으로 하면서, 토양수분 처리는 토양수분 장력 (matric potential과 solution potential의 합 : tension의 단위로 표 시)을 기준으로 하여 관개시점 $20 \mathrm{kPa}(0.2 \mathrm{bar})$ 처리 구, 50 $\mathrm{kPa}(0.5 \mathrm{bar})$ 처리 구, $100 \mathrm{kPa}(1.0 \mathrm{bar})$ 처리 구 및 강우 차단에 의한 한발 처리 구를 두었으며, 1986년에는 1984년 과 동일포장에서 각 처리 구 면적도 동일한 규모로 하여, 토 양수분 3 수준 (관개시점 $20 \mathrm{kPa}$, 자연강우의 무관개, 강우 차단의 한발조건) $\times$ 시비량 4 수준 $($ 무비, 표준시비량의 0.5 배, 표준시비량, 표준시비량의 1.5 배)의 총 12 처리 구를
두었고, 관개종점은 $10 \mathrm{kPa}$ (0.1 bar)로 하였다 (Eom et al., 1984; 1986).

콩 재배는, 1984 년의 경우 맥후작으로 6 월 15 일 파종하여 10 월 30 일 수확하였으며, 1986년의 경우 콩 단작으로 5 월 2 일 파종하여 10 월 20 일 수확하였다.

콩 재배기간 중 지하 $100 \mathrm{~cm}$ 깊이까지 $10 \mathrm{~cm}$ 간격으로 토양 용적 수분 함량 및 근권 물 보유량의 변화량 $(\mathrm{dS})$ 은 중 성자 수분측정기 (Neutron Probe - CPN model)를 이용하 여 경시적으로 측정하였으며, 토양 수분 장력 (H: bar)은 장 력이 낮은 경우는 토양 수분 함량 측정치로부터 공시토양의 토양 수분 특성 곡선 (SMCC: Soil Moisture Characteristic Curve)을 이용하여 (Eom et al., 1983; Klute, 1986) 장력을 산정하였으며, 장력이 $50 \mathrm{kPa}$ 이상인 경우는 자체 제작한 Gypsum block을 이용하여 측정하였다.

콩의 증발산량 (ET: Evapotranspiration)은 식 (1)에 근거 하여 산정하였다 (Blaney \& Criddle, 1962; Eom et al., 1995; Ward et al., 2004).

$$
\mathrm{ET}=\int_{t 1}^{t 2} \int_{z 1}^{z 2}[\mathrm{P}+\mathrm{I}+\mathrm{C}-\mathrm{R}-\mathrm{D}-\mathrm{dS}] \mathrm{dz} \mathrm{dt}
$$

단, t: 시간, z: 깊이, P: 강우량 (Precipitation), I: 관개 량 (Irrigation), C: 모세관 상승량 (Capillary rising), R: 유 거량 (Run-off), D: 배수량 (Drainage), dS: 근권 물 보유량 의 변화량 (Change of water storage in root zone).

$\mathrm{P}$ 는 우량계 측정치, $\mathrm{I}$ 는 계량기 측정치, $\mathrm{R}$ 은 예측모형에 의한 예측치 이며, $\mathrm{C}$ 와 $\mathrm{D}$ 는 깊이별 경시적 토양수분함량의 변화량에 근거하여 산정하였다.

콩 수량은 처리구별 전 개체를 수확 후 생체중을 조사한 후 일정량의 표본을 채취하여 건조 시켜 (Oven dry) 건물 수량 (Ya or Ym: Yield, $\left.\left[\mathrm{kg} 10 \mathrm{a}^{-1}\right]\right)$ 으로 환산 산정하였다.

처리구별 콩 수량지수 (YI: Yield Index)는 식 (2)와 같이 산정하였다.

$\mathrm{YI}=[\mathrm{Ya} / \mathrm{Ym}]$

단, Ya: 처리구별 수량, Ym: 해당년도 최대수량을 나타 낸 처리구의 수량, $\mathrm{ETa}$ 처리구별 $\mathrm{ET}, \mathrm{ETm}$ : 해당년도 최대 $\mathrm{ET}$ 를 나타낸 처리구의 ET.

콩의 수량 반응 지수 (YRF: Yield Response Factor)는 식 (3)과 같이 산정하였다.

$\mathrm{YRF}=[\mathrm{YI} /(\mathrm{ETa} / \mathrm{ETm})]$

콩의 증발산량 지수 (ETI: Evapotranspiration Index)는 식 (4)와 같이 산정하였다. 
$\mathrm{ETI}=(\mathrm{ETa} / \mathrm{PET})$

단, PET: 해당년도의 잠재 증발산량 (Potential

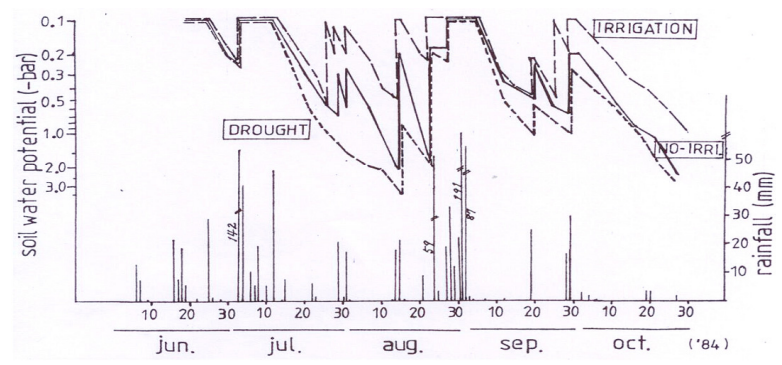

Fig. 1. Change of the soil water potential and rainfall in 1984.

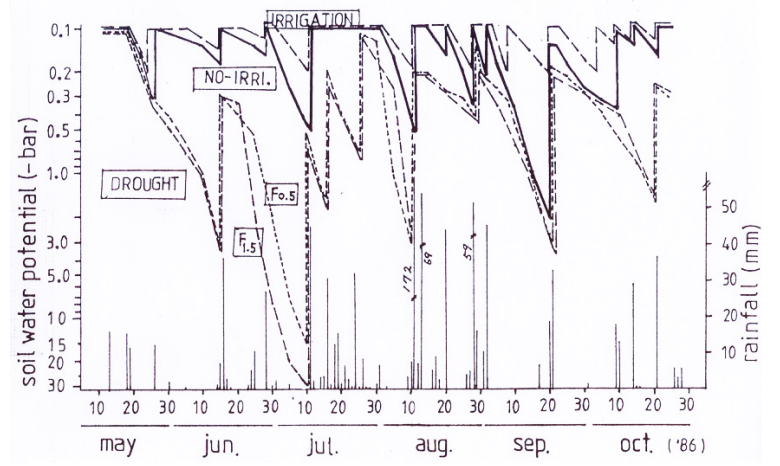

Fig. 2. Change of the soil water potential and rainfall in 1986.
Evapotranspiration).

또한, PET (Penman, 1948)는 본 연구 시험포장에 $2 \mathrm{~m} \times$ $2 \mathrm{~m} \times 1.5 \mathrm{~m}$ 의 Lysimeter를 설치하여 잔디를 재배하며 실 측한 결과 $(\mathrm{Im}, 1987)$ 를 인용하였다.

\section{Results and Discussion}

토양수분 장력의 변화 양상 콩 생육기간 중 강우량 과 각 처리구별 근권 $15 \mathrm{~cm}$ 깊이 토양 수분 장력의 변화양 상은 1984 년 및 1986 년의 경우 각각 Fig. 1 및 Fig. 2 와 같으 며, 1984 년 경우 자연강우 무관개 조건에서는 토양 수분 장 력이 $2.0 \mathrm{bar}(20 \mathrm{kPa})$, 강우 차단에 의한 한발 조건에서는 토양 수분 장력이 $3.0 \mathrm{bar}(300 \mathrm{kPa})$ 까지 높았으며, 1986년 경우 표준시비량 1.5 배의 한발 조건에서 $30 \mathrm{bar}(3 \mathrm{MPa})$ 까 지 높아, 2 개년 모두 한발이 극심한 편이었다. 또한 1986년 한발 조건에서의 토양수분 장력은 표준시비량의 0.5 배 처리 구 (F 0.5)에서는 $15 \mathrm{bar}(1.5 \mathrm{MPa}$ )까지 높았으나, 표준시비 량의 1.5배 처리구 (F 1.5)에서는 $30 \mathrm{bar}$ (3 MPa)까지 높아 졌다. 이는 다량의 시비에 의하여 근권 토양수분의 이온농 도가 높아져 토양 수분의 solution potential이 낮아져 matric potential과의 합으로 측정되는 토양 수분 장력이 더 높았다 고 판단된다.

Table 1. Yield and yield response factor (YRF) of soybean as affected by soil water tension and fertilizer level.

\begin{tabular}{lcccc}
\hline \hline Treatment No. & Irrigation point $(\mathrm{kPa})$ & $\begin{array}{c}\text { Fertilizer level (ratio to } \\
\text { the standard amount) }\end{array}$ & Yield (kg/10a) & YRF* \\
\hline $84-0.2$ & 20 & 1.0 & 282.37 & 1.00 \\
$84-0.5$ & 50 & 1.0 & 242.51 & 0.92 \\
$84-1.0$ & 100 & 1.0 & 239.88 & 1.07 \\
$84-D r$ & Non & 1.0 & 171.85 & 0.91 \\
$86-0.2-F 0$ & 20 & 0 & 264.01 & 0.78 \\
$86-0.2-F 0.5$ & 20 & 0.5 & 281.54 & 0.85 \\
$86-0.2-F 1.0$ & 20 & 1.0 & 339.37 & 0.80 \\
$86-0.2-F 1.5$ & 20 & 1.5 & 263.94 & 1.05 \\
$86-N o n-F 0$ & Non & 0 & 259.39 & 0.84 \\
$86-N o n-F 0.5$ & Non & 0.5 & 254.51 & 0.84 \\
$86-N o n-F 1.0$ & Non & 1.0 & 302.18 & 0.78 \\
$86-N o n-F 1.5$ & Non & 1.5 & 244.59 & 0.96 \\
$86-D R-F 0$ & Non & 0 & 111.75 & 0.74 \\
$86-D R-F 0.5$ & Non & 0.5 & 150.77 & 0.98 \\
$86-D R-F 1.0$ & Non & 1.0 & 165.07 & 0.87 \\
$86-D R-F 1.5$ & Non & 1.5 & 131.22 & 1.16 \\
\hline
\end{tabular}

* $\mathrm{YRF}=[(\mathrm{Ya} / \mathrm{Ym}) /(\mathrm{ETa} / \mathrm{ETm})]$, where, Ya: Yield, Ym: The maximum yield, ETa: Evapotranspiration, ETm: The maximum evapotranspiration 
Table 2. Average daily ET (ETa), drought days (Dr) and the maximum soil water tension (Hmax) during soybean cultivation.

\begin{tabular}{|c|c|c|c|c|}
\hline Treatment No. & Irrigation point $(\mathrm{kPa})$ & $\begin{array}{l}\text { Fertilizer level } \\
\text { (ratio to the standard amount) }\end{array}$ & Yield (kg/10a) & YRF* \\
\hline $84-0.2$ & 20 & 1.0 & 282.37 & 1.00 \\
\hline $84-0.5$ & 50 & 1.0 & 242.51 & 0.92 \\
\hline $84-1.0$ & 100 & 1.0 & 239.88 & 1.07 \\
\hline 84-Dr & Non & 1.0 & 171.85 & 0.91 \\
\hline $86-0.2-\mathrm{F} 0$ & 20 & 0 & 264.01 & 0.78 \\
\hline $86-0.2-F 0.5$ & 20 & 0.5 & 281.54 & 0.85 \\
\hline $86-0.2-\mathrm{F} 1.0$ & 20 & 1.0 & 339.37 & 0.80 \\
\hline $86-0.2-\mathrm{F} 1.5$ & 20 & 1.5 & 263.94 & 1.05 \\
\hline 86-Non-F0 & Non & 0 & 259.39 & 0.84 \\
\hline 86-Non-F0.5 & Non & 0.5 & 254.51 & 0.84 \\
\hline 86-Non-F1.0 & Non & 1.0 & 302.18 & 0.78 \\
\hline 86-Non-F1.5 & Non & 1.5 & 244.59 & 0.96 \\
\hline 86-DR-F0 & Non & 0 & 111.75 & 0.74 \\
\hline 86-DR-F0.5 & Non & 0.5 & 150.77 & 0.98 \\
\hline 86-DR-F1.0 & Non & 1.0 & 165.07 & 0.87 \\
\hline 86-DR-F1.5 & Non & 1.5 & 131.22 & 1.16 \\
\hline
\end{tabular}

*Dr: Days that the soil water tension was more than $50 \mathrm{kPa}$.

\section{토양수분 조건과 시비수준에 따른 콩 수량과 한발}

지표 콩의 처리구별 수량 (건물중 $\mathrm{kg} 10 \mathrm{a}^{-1}$ )은 Table 1에 서처럼, 최대 토양 수분 장력이 $300 \mathrm{kPa}$ 까지 높았던 ('84) 한발 조건에서의 콩 수량은 관개시점 $20 \mathrm{kPa}$ 조건의 $61 \%$ 밖에 되지 않았다. 특히 최대 토양 수분 장력이 $1.5 \mathrm{MPa}$ 3.0 MPa 까지 높았던 ('86) 한발 조건에서의 콩 수량은 관개 시점 $20 \mathrm{kPa}$ 및 표준시비량 (F 1.0) 조건의 $33 \sim 49 \%$ 밖에 되지 않았다. 이로 볼 때 한발에 의한 콩 수량의 감소율은 매우 민감하게 반응한다고 사료된다.

작물 재배 기간 중 한발 조건이 되면 토양으로부터의 증 발량과 작물에 의한 증산량 모두 감소하게 되어 증발산량 또한 감소하게 된다. 콩의 상대 증발산량 $(\mathrm{ETa} / \mathrm{ETm})$ 감소 에 대한 수량 감소율 $(\mathrm{Ya} / \mathrm{Ym})$ 의 비율인 수량 반응 지수 (YRF)는 식 (3)에 의거 산정한 결과 (Table 1) 전체 평균은 0.91 이었다. 이는 콩의 수량 감소율은 증발산량 감소율의 $91 \%$ 정도라고 해석할 수 있으며, 시비량이 동일하고 토양 수분 조건이 다른 1984년 경우 YRF는 0.91 1.07 범위이었 으며, 시비량과 토양 수분 조건 모두 다른 1986 년의 경우 YRF는 0.74 1.16 범위이었다.

콩 생육기간 동안 각 처리구별 평균 일 증발산량 $(\mathrm{ETa}$ $\left.\left[\mathrm{mm} \mathrm{day}{ }^{-1}\right]\right)$, 토양 수분 장력 $50 \mathrm{kPa}$ 이상인 한발 일수 $(\mathrm{Dr}$ [days]) 및 최대 토양 수분 장력 $(\mathrm{Hmax}[\mathrm{kPa}])$ 는 Table 2 와 같으며, 이들의 측정치를 이용하여 식 (2)에 의한 상대 수량 지수 (YI)와 식 (4)에 의한 증발산량 지수 (ETI), Hmax 및 $\mathrm{Dr}$ 과의 관련성을 분석한 결과는 다음과 같다.

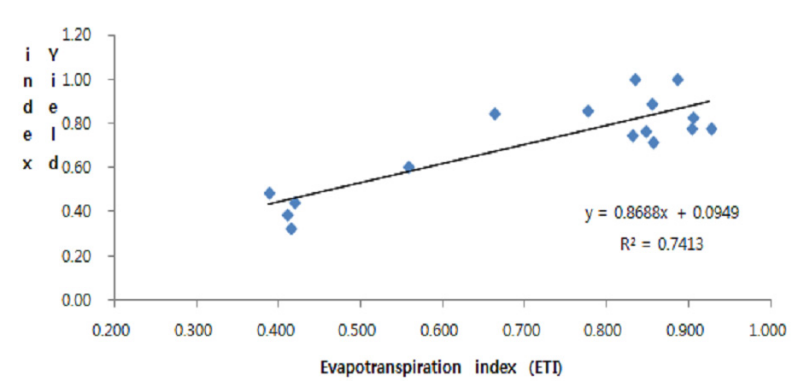

Fig. 3. Relationship between yield index and evapotranspiration index (ETI).

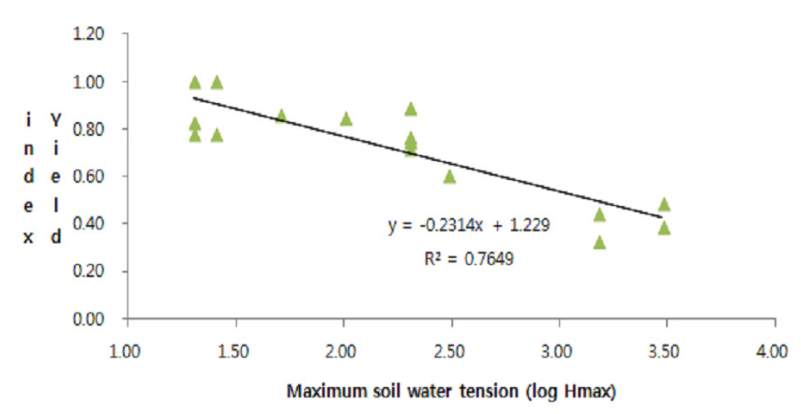

Fig. 4. Relationship between yield index and maximum soil water tension $(\log [\mathrm{Hmax}])$.

(1) YI와 ETI의 상관관계는 Fig. 3 및 식 (5)와 같다.

$\mathrm{YI}=0.87 \cdot(\mathrm{ETI})+0.09\left(\mathrm{R}^{2}=0.741^{* *}\right)$ 


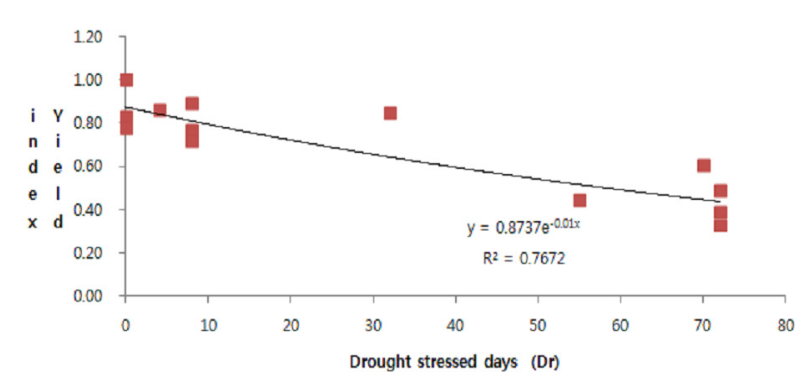

ig. 5. Relationship between yield index and drought stressed days (Dr).

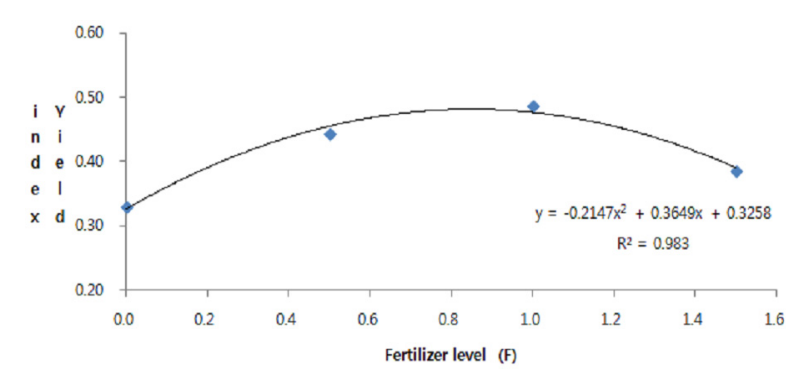

Fig. 6. Relationship between yield index and fertilizer level (F).

(2) $\mathrm{YI}$ 와 $\mathrm{Hmax}$ 의 상관관계는 Fig. 4 및 식 (6)과 같다.

$\mathrm{YI}=1.23-0.23 \cdot \log (\mathrm{Hmax})\left(\mathrm{R}^{2}=0.765^{* *}\right)$

(3) YI와 Dr의 상관관계는 Fig. 5 및 식 (7)과 같다.

$$
\mathrm{YI}=0.874 \cdot \exp (-0.01 \cdot \mathrm{Dr})\left(\mathrm{R}^{2}=0.767^{* * *}\right)
$$

상기 관련 지수들 중 $\mathrm{ETI}$ 와 $\mathrm{Hmax}$ 를 이용하여 YI를 예측 하는 경우는 적습조건부터 한발조건까지 전 범위에서 적용 가능하며, $\mathrm{Dr}$ 을 이용하는 경우는 약한 한발 $(50 \mathrm{kPa}$ 이상 $)$ 부 터 심한 한발 $(0.3 \mathrm{MPa}$ 이상)까지의 한발 조건에서만 적용 가능하다고 판단된다. 특히 심한 한발의 경우, 시비량 $(\mathrm{F})$ 과 YI와의 관계는 Fig. 6 및 식 (8)과 같다.

$$
\mathrm{YI}=-0.21 \cdot \mathrm{F}^{2}+0.36 \cdot \mathrm{F}+0.33\left(\mathrm{R}^{2}=0.983^{* *}\right)
$$

이로 볼 때, 한발이 심한 경우는 적정시비량의 경우에 콩 생육이 가장 좋으며 이보다 많은 량을 시비할 경우 다량의 시비량에 의하여 토양수분 solution potential과 matric potential의 합으로 결정되는 토양수분 장력이 증가함에 따 라 콩 증발산량의 부족 때문에 수량이 감소한다고 판단되 며, 1982년 동일한 시험포장에서 배추를 공시작물로 하여 콩 1986년 경우와 동일한 처리구를 두고 시험한 결과와도 유사한 경향을 보였다 (Eom et al., 1983).
본 연구는, 상기 결과의 한발관련 지표들을 이용하여 금 후 한발에 대한 타 작물별 수량반응에 관한 연구 및 한발평 가에 기여할 수 있으리라 사료된다.

\section{Conclusions}

1. 콩의 증발산량 부족율 $(\mathrm{ETa} / \mathrm{ETm})$ 에 대한 수량 감소율 (Ya/Ym)의 비율인 수량반응 지수 (YRF: Yield Response Factor)는 0.91이었으며, 토양수분 조건 차이 및 시비수 준 차이에 의한 $\mathrm{YRF}$ 의 변화범위는 각각 ('84) 0.91 1.07 및 ('86) $0.74 \sim 1.16$ 이었다.

2. 콩 생육기간 중 콩 증발산량 $(\mathrm{ETa})$ 의 잠재 증발산량 (PET)에 대한 비율인 증발산 지수 (ETI: Evapotranspiration Index)와, 해당 조건별 콩 건물중 수량 (Ya)의 최 대 수량 $(\mathrm{Ym})$ 에 대한 비율인 상대 수량 지수 (YI: Yield Index)와의 관계는; YI $=0.87 \cdot(\mathrm{ETI})+0.09$ 이었다.

3. 콩 생육기간 중 한발 스트레스의 지표인 최대 토양 수분 장력 (Hmax $[\mathrm{kPa}]$ : Maximum Soil Water Tension)과 YI 과의 관계는 : YI = $1.23-0.23 \cdot \log (\mathrm{Hmax})$ 이었다.

4. 콩 생육기간 중 한발 스트레스의 또 다.른 지표인 한발 지속 기간 $(\mathrm{Dr}$ [days])과 $\mathrm{YI}$ 과의 관계는 : $\mathrm{YI}=0.877 \cdot \exp$ $(-0.01 \cdot \mathrm{Dr})$ 이었다.

5. 콩 생육기간 중 $\mathrm{Hmax}$ 가 $3 \mathrm{MPa}$ 인 극심한 한발 경우 시 비량 ( $\mathrm{F}$ :표준시비량에 대한 비율)에 따라 $\mathrm{YI}$ 는 0.91 1.07 범위이었으며, $\mathrm{F}$ 와 $\mathrm{YI}$ 과의 관계는: $\mathrm{YI}=-0.21 \cdot \mathrm{F}^{2}$ $+0.36 \cdot F+0.33$ 이었다.

\section{References}

Blaney, H.F. and W.D. Criddle. 1962. Determining consumptive use and irrigation water requirement. Agr. Res. Ser. USDA Tech. Ball. 1275:1-59.

Eom, K.C., E.R. Son, and S.H. Yoo. 1983. Fertilizer response of chinese cabbage to soil water potential. Korean J. Soil Sci. \& Fert. 16:98-105.

Eom, K.C., K.C. Song, K.S. Ryu, Y.K. Sonn, and S.E. Lee. 1995. Model equations to estimate the soil water characteristics curve using scaling factor. Korean J. Soil Sci. \& Fert. 28:227-232.

Eom, K.C. and K.S. Ryu. 1984. NAAS annual research report, RDA. (In Korean).

Eom, K.C. and K.S. Ryu. 1986. NAAS annual research report, RDA. (In Korean).

Eom, K.C., P.K. Jung, T.W. Kim, S.Y. Yoo, and S.H. Park. 2011. Development of the model to estimate potential evapotranspiration in Korea. Korean J. Soil Sci. \& Fert. 44(5) :674-678.

Eom, K.C., S.K. Ha, S.O. Hur, Y.S. Jung, and K.S Ryu. 2009. 
Soil water. Korean J. Soil Sci. \& Fert. 42:102-125.

Im, J.N. 1987. Modeling of estimating soil moisture, evapotranspiration and yield of chinese cabbages from meteorological data at different growth stages. Seoul Nat'l Univ. pH. D thesis. pp. 27-34.

Kim, W.H., J.E. Lee, and Y.H. Ryu. 2000. Yield and seed quality as affected by water deficit at different reproductive growth stages in soybean.

Klute, A. 1986. Water retention: laboratory methods, in methods of soil analysis. Madison. Wisconsin. USA. pp. 635-662.

Lee, J.M., J.H. Seo, H.S. Cho, C.G. Kim, S.P. Eom, and T.K. Oh.
2004. Effect of soil moisture on the growth and development of soybeans (Glycine max (L.) Merr.).

Penman, H.L. 1948. Natural evaporation from open water, bare soil and grass. Proc. Roy. Soc. London. A193:120-146.

RDA. 1984. Research report for drought and high temperature hazard. pp.46-56 (In Korean).

Son, C.K., S.C. Park, C.Y. Kim, and B.S. Choi. 1996. Effects of water stress on growth characteristics and grain yield of soybean.

Ward, A. and S. Trimble. 2004. Environmental hydrology. Lewis Publishers, USA. 465. 